\title{
Pathogenicity of field and laboratory-grown inoculum of Neonectria galligena on potted apple trees
}

\author{
R.W.A. Scheper, B.M. Fisher and P.N. Wood \\ The New Zealand Institute for Plant E Food Research Limited, Private Bag 1401, Havelock North, \\ New Zealand \\ Corresponding author: reiny.scheper@plantandfood.co.nz
}

European canker, caused by Neonectria galligena, is an important disease of apple trees worldwide. In this study, methods were developed for conidium production in culture and for testing the pathogenicity of $N$. galligena. Conidia produced in culture were one- or two-celled, while conidia collected from cankers were multi-celled. Isolate ICMP9472 produced enough conidia in culture to produce inoculum $\left(2 \times 10^{5}\right.$ conidia/ml $)$ to test the pathogenicity in comparison with that of conidia harvested from apple cankers from Motueka (field inoculum) and a two-day-old suspension of conidia from Motueka apple cankers, on potted 'Royal Gala' trees in a glasshouse under continual misting. The germination rates of the three inocula were similar (50-79\%). Two months after inoculation, all inoculated wounds were infected, regardless of inoculum source. However, cankers caused by field inoculum (fresh and twoday-old) were significantly larger (average $10.8 \mathrm{~mm}$ and $10.6 \mathrm{~mm}$, respectively) than those caused by isolate ICMP9472 $(5.1 \mathrm{~mm})$. Six months after inoculation, cankers caused by fresh field inoculum were significantly larger than those caused by 2-day-old inoculum, which were significantly larger than those caused by isolate ICMP9472. In addition, cankers caused by fresh field inoculum were significantly more active than those caused by older field inoculum or isolate ICMP9472.

\section{Comparing methods to determine European canker resistance in apple tree accessions}

\author{
R.W.A. Scheper and B.M. Fisher \\ The New Zealand Institute for Plant E Food Research Limited, Private Bag 1401, Havelock North, \\ New Zealand \\ Correspondingauthor: reiny.scheper@plantandfood.co.nz
}

Pruning cuts made in summer, and pruning cuts, leaf scars and score wounds made in autumn were inoculated to compare their suitability to discriminate for European canker resistance among apple accessions. When pruning cuts were inoculated in summer, the mean lesion size varied between accessions, with 'Royal Gala' displaying significantly larger lesions than 15 other accessions, 17 to 43 days after inoculation $(\mathrm{P}<0.001)$. 'Robusta 5' (R5) and 'M.9' had the smallest lesions 43 days after inoculation. When pruning cuts were inoculated in autumn, R5 displayed the smallest lesions among 12 accessions, 4 and 10 months after inoculation, while 'M.9', 'Royal Gala' and 'Granny Smith' had significantly larger lesions than R5 ( $\mathrm{P}<0.001)$. Inoculated score wounds of 'Granny Smith' and 'Jonathan' developed significantly smaller lesions than those of 'M.9' $(\mathrm{P}<0.001)$. When leaf scars were inoculated, 'Jonathan' developed symptoms on only $10 \%$ of the leaf scars, and lesions were significantly smaller than in other accessions $(\mathrm{P}<0.001)$. 'Royal Gala' had the largest lesions, and 56\% of leaf scars of 'M.9' developed symptoms. This study has shown that the expression of the disease in various accessions differs according to the method and timing of inoculation. 